\title{
EL CULTO A LA TIERRA, LOS MONTES Y EL AGUA Semejanzas entre los Andes y Mesoamérica
}

\section{Silvia Limón Olvera}

Tanto los pueblos andinos como los mesoamericanos se caracterizaron por tener la agricultura como la principal actividad económica, la cual, según las antiguas ideas religiosas, era controlada por diversos seres sagrados personificados en deidades. La dependencia de estas sociedades de determinadas entidades sobrenaturales que decidían la producción del sustento dio lugar a la sacralización de algunos elementos de la naturaleza y a considerar la necesidad de dedicarles constantes ceremonias para propiciar el adecuado desarrollo de los cultivos. Dichas prácticas estuvieron sustentadas en diversas concepciones que constituyeron formas particulares de entender y explicar el mundo. Asimismo, en estas cosmovisiones, los elementos naturales deificados que estaban asociados a la actividad agrícola fueron de gran importancia. Por ello, en los sistemas religiosos de los pueblos prehispánicos andinos y mesoamericanos ocuparon un lugar central las deidades relacionadas con la tierra y la lluvia, así como algunos accidentes geográficos, entre los que destacan los montes y las cuevas. 


\section{SILVIA LIMÓN OLVERA}

En este espacio presentaremos algunos de los principales conceptos que tenían los incas y los mexicas en relación con las entidades arriba referidas. De igual forma, trataremos de señalar las semejanzas que existen entre diversos aspectos de ambas cosmovisiones, sin perder de vista las particularidades propias de cada uno de estos sistemas religiosos. Aquí cabe mencionar que tanto los incas como los mexicas fueron pueblos que vivieron en la etapa previa a la conquista española y les tocó enfrentar este proceso. Sin embargo, también debido a ello, contamos con importante información sobre dichas sociedades en crónicas coloniales que proporcionan datos relevantes que permiten realizar un análisis de las antiguas creencias.

Según las cosmovisiones de diversos pueblos andinos y mesoamericanos, la tierra, en general, así como las montañas y las cuevas, en particular, han sido consideradas como espacios sagrados, ya que algunos de estos sitios fueron considerados como residencia o personificación de algunos seres sobrenaturales.

El carácter sacro de estos espacios se debe a que ocupan un lugar importante en el paisaje y en la cosmovisión, puesto que son característicos del ámbito en el que se desarrollaron diversos pueblos de ambas regiones, como fue el caso de los incas y de los mexicas. Estas dos sociedades estuvieron asentadas en un medio ambiente dóminado por montañas y quebradas, en donde es común la formación de cavernas. El predominio de ese paisaje accidentado propició que los montes y cuevas tuvieran un lugar muy importante en la cosmovisión. Así, por ejemplo, en ambas sociedades algunos cerros fueron concebidos como entidades protectoras de comunidades, mientras que otros fueron objeto de culto por personificar a algunas deidades o por ser considerados como morada de seres sagrados que, en la mayoría de los casos, estaban relacionados con la agricultura.

Igualmente, las cuevas, las quebradas y los montes fueron elementos relevantes en los mitos de origen y fueron explicados a través de su particular visión del mundo, en la que la naturaleza y lo sobrenatural se encuentran interrelacionados, lo cual determinó, a su vez, la realización de diversas ceremonias en dichos sitios. Lo anterior se debe a que los pueblos aquí referidos consideraron a la 
geografía como sagrada y a sus accidentes como expresiones de lo sobrenatural ${ }^{1}$. Así, las fuerzas y los componentes de la naturaleza que incidieron en la vida de la sociedad y del individuo fueron elevados a la categoría de dioses. De igual manera, observamos que existió una liga íntima entre los dos pueblos - el inca y el mexica-y el medio geográfico que se manifestó a través de relaciones de parentesco, de interdependencia y de intercambio recíproco de ofrendas y dones (el ser humano da ofrendas a los dioses de los montes y de la tierra y, a cambio, éstos le proporcionan lo necesario para satisfacer sus necesidades). En consonancia con lo anterior, diferentes elementos del medio natural de su entorno fueron considerados sagrados, es decir, en la región andina tuvieron la categoría de huaca, mientras que otros sitios, llamados en esta misma región pakarinas, fueron identificados como lugares de origen de los pueblos. Tal es el caso de Tampu Tocco, de donde salieron los hermanos Ayar. Por otro lado, según la tradición prehispánica, diversos pueblos del altiplano central de México tuvieron su origen en Chicomóztoc, "lugar de las siete cuevas", que se encontraba en el interior del cerro de Culhuacan; mientras que diversos grupos mayas, como los quichés y cakchiqueles, según sus antiguas crónicas, dicen que tuvieron su origen en lugares llamados Vucub Zivan, "Siete Barrancas" y Vucub Pec, "Siete cuevas"2. Vemos que tanto los pueblos andinos como los mesoamericanos concibieron el paisaje natural bajo los cánones de una geografía, cuyos puntos de referencia eran elementos sagrados que tuvieron como base las concepciones míticas, de lo cual se deriva una concepción simbólica del espacio.

1 Federico Kauffman-Doig, Introducción al Perú antiguo. Una nueva perspectiva, Lima, Editores Kompaktos, 1990, p. 198. Franklin Pease G. Y., Las crónicas y los Andes, Pontificia Universidad Católica del Perú, Instituto Riva Agüero y Fondo de Cultura Económica, 1995, p. 272 (Sección de Obras de Historia).

2 Memorial de Sololá. Anales de los cakchiqueles, traducción, introducción y notas de Adrián Recinos, México, FCE, 1950, p. 41 y 47; y Popol-Vuh. Las antiguas historias del Quiché, $4^{\mathrm{a}}$ ed., traducción, introducción y notas de Adrián Recinos, México, FCE, 1979, p. 110, 112, 116. 


\section{SILVIA LIMÓN OLVERA}

\section{ESQUEMA COSMOGÓNICO}

El esquema cosmogónico de los pueblos andinos y mesoamericanos prehispánicos estuvo caracterizado por la concepción cíclica del devenir, puesto que hay una sucesión de diferentes edades en las que cada creación es precedida de una destrucción provocada por alguna catástrofe (lluvia de fuego o diluvio). De esta manera, la creación no parte de la nada, sino que implica la preexistencia de un mundo o de una humanidad que es destruida para dar inicio a una nueva creación, es decir, para establecer un nuevo orden. Dentro de esta concepción, en el caso andino tuvo un lugar importante la honda, pues según un mito de Huamachuco, el dios Catequil aniquiló a los guachemines, primeros pobladores de la región, con unas hondas que el dios Huamansuri había dejado en la tierra. Por otra parte, el mito de los hermanos Ayar menciona que uno de ellos, llamado Ayar Cache, durante el trayecto para encontrar el lugar prometido, iba arrojando piedras con su honda, con lo cual deshizo cerros y formó quebradas. El caso mexica es diferente, puesto que, según los mitos, después de un diluvio devastador, los dioses Tecatlipoca y Quetzalcóatl bajaron del cielo a la diosa de la tierra, que tenía forma de un peje lagarto que en todas las coyunturas tenía ojos y bocas, la dividieron en dos porciones, una de ellas fue elevada al ciélo, mientras que la otra fue colocada encima de las aguas primigenias. Las diferentes partes del cuerpo de este ser sagrado conformaron diversos elementos de la naturaleza. Así, sus cabellos constituyeron los árboles, las flores y los arbustos; su piel formó la yerba y las flores menudas; sus múltiples ojos configuraron pozos, fuentes y pequeñas cuevas; sus bocas ríos y grandes cavernas y su nariz valles y montañas ${ }^{3}$.

\section{COSMOLOGÍA}

En lo que se refiere a la estructura del mundo, los datos que presentan las fuentes muestran una concepción muy similar entre los

3 "Histoire du Mechique", en Teogonía e historia de los mexicanos. Tres opúsculos del siglo XVI, $2^{\mathrm{a}}$ edición, preparada por Ángel María Garibay K, México, Purrúa, 1973, p. 108. 


\section{EL CULTO A LA TIERRA, LOS MONTES Y EL AGUA}

mexicas y los incas, ya que según la cosmovisión de estos dos pueblos el cosmos estuvo dividido, en sentido vertical, en tres grandes sectores: la parte alta llamada hanan pacha entre los incas e ilhuícatl entre los mexicas; el ámbito inferior que corresponde al interior de la tierra, denominado respectivamente urin o ucu pacha y mictlan; y el espacio intermedio del cosmos, que es identificado con la superficie terrestre conocida como kay pacha y tlaltícpac.

De acuerdo con Franklin Pease, esta imagen ternaria del cosmos pudo haber sido un traslado de la imagen europea, pues este autor considera que para los incas sólo había dos mundos: el hanan pacha (mundo alto) y el urin pacha o ucu pacha (mundo de abajo o inframundo); mientras que la kay pacha o plano intermedio correspondería al lugar de unión o encuentro de los sectores alto y bajo4. Este esquema también puede aplicarse a la cosmología mexica, ya que en ambos casos el plano terrestre constituía la intersección de los dos extremos verticales del cosmos, el arriba y el abajo, residencia de los dos principios primordiales generadores del mundo, como se verá más adelante.

El ámbito intermedio, que correspondía a la superficie terrestre, era concebido por los dos pueblos como un rectángulo dividido en cuatro partes, cuyas esquinas estaban determinadas por los solsticios, es decir, por los puntos extremos norte y sur de los horizontes oriente y poniente, es decir, por donde sale y se mete el sol, respectivamente $e^{5}$. De igual forma, en ambas cosmovisiones el punto central del plano terrestre constituía un sitio privilegiado, puesto

4 Franklin Pease G., Los incas. Una introducción, $3^{\mathrm{a}}$ ed., Lima Perú, Fondo Editorial de la Pontificia Universidad Católica del Perú, 1994, p. 146 (Biblioteca "Lo que debo saber", 1).

5 Según J. Alden Mason, inicialmente los marcadores que señalaban el trayecto anual del sol por el horizonte fueron las montañas, pero el inca Pachacuti mandó construir, en lo más alto de los cerros, cuatro torres de cantería al este y otras tantas en el oeste, es decir, por donde sale y se mete el sol para señalar los puntos extremos del sol y los tiempos de siembra y de cosecha. J. Alden Mason, Las antiguas culturas del Perú, trad. de Margarita Villegas de Robles, México, FCE, 1962. En relación con lo anterior, hay que mencionar que, de acuerdo con Pease, las fiestas más importantes de los incas fueron las relacionadas con los solsticios: Inti Raymi en junio, que corresponde al solsticio de invierno, y Capac Raymi en diciembre, que corresponde al solsticio de verano. Pease, Los incas, p. 153-154. 


\section{SILVIA LIMÓN OLVERA}

que allí se encontraba el axis mundi y, por tanto, era donde se manifestaban las fuerzas sagradas y el lugar desde el cual se podía mantener el equilibrio del mundo. De esta manera los incas y los mexicas, para legitimar su poderío, consideraron que sus respectivas ciudades se encontraban en el centro.

Para los incas, el esquema cuatripartita del mundo correspondió al Tawantinsuyu, que estuvo dividido en cuatro partes: Antisuyu, Chinchaysuyu, Contisuyu y Collasuyu, y en cuyo centro se encontraba ubicada la ciudad de Cusco 6 . Por su parte, los mexicas dividieron el mundo conocido en cuatro direcciones y creían que en cada esquina y en el centro se encontraban sendos árboles cósmicos que sostenían la bóveda celeste. De igual forma, dividían a la ciudad de México Ténochtitlan, localizada en el punto central, en cuatro partes llamadas campan, cuyo punto medular era el recinto ceremonial.

\section{CONCEPCIÓN DUAL: LOS PRINCIPIOS MASCULINO Y FEMENINO}

En las dos cosmovisiones predominó una taxonomía binaria, la cual se manifestó en la concepción de dos principios opuestos y complementarios, identificados con los sexos masculino y femenino, los cuales fueron deificados y personificados en dos seres primordiales y generativoś. El principio masculino, asociado a la parte alta del cosmos y que tuvo como característica la facultad de la fecundación, fue personificado en la zona andina por las diversas manifestaciones del dios creador: Viracocha, Pachacámac, Cuniraya y Tonapa, entre otras, $y$, asimismo, agrupó a deidades como Illapa, dios del trueno y de la lluvia, y a Inti o dios del sol, divinidad particular del linaje gobernante de Cusco. Por otro lado, la contraparte femenina suceptible de ser fecundada en ambas cosmovisiones, se localizaba en la parte baja del cosmos y estaba personificada en la

6 Según Pease, en este plano también estaba implicado el esquema dual de lo alto o hanan y lo bajo o urin. De esta manera, el esquema binario también tuvo su correspondencia en la división política del Tawantinsuyu, pues dos de los cuatro suyus (Antisuyu y Chinchaysuyu) correspondían a la parte alta o hanan y los otros dos (Contisuyu y Collasuyu) a la parte baja o urin. Ibid., p. 96-97. 
zona andina por Pachamama y entre los mexicas por la deidad terrestre, que ostenta diversos nombres como Coatlicue, Tonantzir, Cihuacóatl, Quilaztli y Toci. Para el caso andino, Federico KauffmanDoig establece que la pareja primigenia estuvo compuesta por el dios de la lluvia y por la diosa de la tierra y Franklin Pease señala que, en los mitos de creación, las deidades celestes fecundan la tierra y luego van al cielo, a los confines del mundo o se convierten en cerros?.

En la religión mexica, las divinidades que representaban a los dos principios generativos se integraban en una sola unidad personificada en Ometéotl (Dios dos) y ésta se desdoblaba en Ometecuhtli, de carácter masculino, y en Omecíhuatl, su contraparte femenina. Asimismo, a cada uno de estos dos principios estuvieron adscritas diversas divinidades, por ejemplo, del lado masculino se encontraban dioses como el del fuego, llamado HuehuetéotlXiuhtecuhtli, con marcada facultad fecundadora ${ }^{8}$, y Huitzilopochtli (dios solar), patrono de los mexicas; mientras que al principio femenino correspondían las diferentes advocaciones del la diosa de la tierra, ya mencionadas, así como las diferentes diosas de los alimentos, entre las que están Xilonen y Chicomecóatl ${ }^{9}$. Cabe mencionar que Ometecuhtli y Omecíhuatl procrearon a cuatro dioses y a dos de ellos, Quetzalcoatl y Tezcatlipoca, les relegaron la creación de la tierra, por tanto, la divinidad dual estaba alejada del ser humano y por ello no era objeto de culto por parte del pueblo.

Con base en lo anterior y en relación con la división dual del cosmos, podemos apreciar que, según ambas cosmovisiones, en el cielo se encontraban los dioses masculinos, creadores, celestes $y$ fecundadores; mientras que el inframundo era el dominio de la diosa madre de la tierra, susceptible de ser fertilizada. Cabe mencionar que esta parte baja del cosmos constituyó también el mundo de los muertos; sin embargo, en este sector se encontraban las posibilida-

7 Ibid., p. 153.

8 Silvia Limón Olvera, El fuego sagrado. Simolismo y ritualidad entre los nahuas según las fuentes documentales, México, INAH-CCyDEL-UNAM, 2001.

9 Para la taxonomía dual entre los mexicas, cfr. Alfredo López Austin, Cuerpo humano e ideología. Las concepciones de los antiguos nahuas, 2 vols., México, IIA-UNAM, 1980. 


\section{SILVIA LIMÓN OLVERA}

des de la vida y de la regeneración de la naturaleza, puesto que era el depósito de las semillas.

\section{LA TIERRA}

La divinidad terrestre, en las dos religiones, fue considerada como la procreadora de los seres humanos, quienes brotaron de sus entrañas, es decir, de las cuevas, aunque algunos pueblos andinos concibieron que el hombre también surgió de manantiales y lagunas, elementos que, asimismo, estaban asociados al subsuelo. De esta manera, en las dos cosmovisiones, la deidad terrestre fue quien dio a luz a los seres humanos; sin embargo, a ellos reclama, tarde o temprano, su retornò a la matriz primordial a través de la muerte. Por tanto, en ambos casos se trató de una divinidad que presentó dos aspectos opuestos y complementarios, pues, por un lado, fue la entidad generosa que creó al hombre y le suministró los alimentos necesarios para su subsistencia, pero, por el otro, también presentó un aspecto terrible, ya que exigía la inmolación de seres humanos para alimentarse, poder sobrevivir como entidad sagrada y, a cambio de esos sacrificios, ella les proporcionaba sus frutos.

Pachamama era una deidad que vivía bajo la tierra y en el interior de las montañas, es decir, su lugar característico era el subsuelo, al cual representaba. Por eso las ofrendas de sebo de llama y hojas de coca, que le daban como pago o tributo, eran depositadas en agujeros cavados en el suelo, que constituían canales que conducían las ofrendas directamente a las entrañas de la Pachamama ${ }^{10}$. En relación con esto puede estar el rito del sacrificio de niños por enterramiento que efectuaban cuando iniciaban la labranza de la tierra en el mes de Chacra Yapuy ${ }^{11}$.

Tanto en los Andes como en Mesoamérica, la deidad terrestre comprendía los territorios en los que se establecían las comuni-

10 Kauffmann-Doig, op. cit., p. 212.

11 Felipe Guamán Poma de Ayala, El primer nueva corónica y buen gobierno, 3 vols., ed. crítica de John V. Murra y Rolena Adorno, trad. y análisis del quechua de Jorge L. Urioste, México, Siglo Veintiuno Editores, 1980 (Colección América Nuestra. América Antigua), vol I, p. 225. 
dades y las parcelas cultivadas. Por ello, fue común en ambas regiones el darle diversas ofrendas, como comida y bebida, en los ritos que efectuaban antes de iniciar la siembra. En relación con esto, los aimaras actuales de Bolivia consideran a Pachamama como una mujer anciana, pues por siglos ha mantenido a sus hijos, pero también es concebida como una madre joven, porque sigue siendo capaz de producir frutos ${ }^{12}$; mientras que los habitantes de Cusco y sus descendientes la identifican como una niña pequeña ${ }^{13}$. Por otro lado, algunas advocaciones de la diosa terrestre de los nahuas eran concebidas como una mujer madura, mientras que en su personificación de Toci era una mujer anciana. De igual forma, tanto los incas como los mexicas consideraban que la diosa de la tierra incluía la topografía con sus montes y valles. Por eso, en el mito de Pachacámac, esta diosa se transformó en un cerro alto llamado "Montaña de la Viuda", además de que estuvo personificada en otros cerros como el Solimana y el Coropuna. Según Pedro Cieza de León, en este último monte de nieve perenne, que se encontraba en la provincia de Condesuyu, había un templo muy estimado y frecuentado por la realeza inca, porque era un oráculo que daba respuestas de continuo. Asimismo, menciona que dicha montaña era objeto de ricas ofrendas de oro y plata y que, en algunas ocasiones, le sacrificaban llamas, cuyes y seres humanos ${ }^{14}$. En lo que se refiere a los mexicas, Diego Durán menciona que en el templo de la diosa de la tierra, llamada Cihuacóatl, localizado en el centro ceremonial de México Tenochtitlan, había diversos ídolos que representaban a todos los montes del valle de México. También, este cronista $y$ Bernardino de Sahagún registran que algunos de los cerros tenían una connotación femenina ${ }^{15}$.

12 Hans van den Berg, "Religión aymara", en La cosmovisión aymara, Hans van den Berg y Norbert Schiffers (Comps.), La Paz, Bolivia, Hisbol-UCB, 1992, p. 296.

13 Pease, Los Incas, p. 147.

14 Pedro Cieza de León, Segunda parte de la Crónica del Perú, $3^{a}$ ed., ed., prólogo y notas de Francesca Cantú, Lima, Pontificia Universidad Católica del Perú, 1996, p. 85-86 (Colección Clásicos Peruanos).

15 Diego Durán, Historia de las Indias de la Nueva Epaña e islas de tierra firme, ed. preparada por Ángel Ma. Garibay K., México, Porrúa, 1967, vol. I, p. 126 


\section{SILVIA LIMÓN OLVERA}

En las dos religiones encontramos la concepción de que la tierra es fertilizada por la lluvia. Asimismo, se conservan mitos sobre la fecundación del principio femenino por dioses masculinos. En relación con esto, existen algunas narraciones procedentes de pueblos nahuas que relatan la caída del cielo de una piedra o de una flecha que fecunda la tierra y da por resultado el surgimiento del ser humano de las entrañas terrestres. De acuerdo con un mito recogido por los agustinos en la región de Huamachuco, el dios Catequil fue a un cerro llamado Guacat y allí cavó con azadas de oro y plata, de donde extrajo al ser humano. Las azadas de oro y plata representan el principio masculino, que, al introducirse en la tierra, la fertiliza para que surja el hombre. En este mito también es importante señalar la equiparación que se hace entre el ser humano y las plantas, lo cual se debe al carácter eminentemente agrícola de los grupos andinos. Por otro lado, Pachamama y Cahuillaco fueron fecundadas por Pachacámac, que se manifestó como un ave; mientras que, según la tradición mexica, Coatlicue, madre de Huitzilopochtli, quedó embarazada por haberse guardado un plumón en su seno' ${ }^{16}$.

Las diosas terrestres están muy relacionadas con la agricultura, puesto que de su mismo cuerpo salen las plantas, por ello presentan nexos con las divinidades de los alimentos. Así, Pachamama estuvo asociada con Saramama, madre del maíz, y Cocamama, madre de la coca. En la iconografía arqueológica andina, Pachamama es representada como conjuntos de papas $y$ mazorcas de maíz múltiples, productos que también aparecen con un aspecto humano femenino, en ocasiones en el momento en que son fecundados por un personaje sobrenatural ${ }^{17}$. Entre los mexicas, las diosas de los mantenimientos también estaban muy relacionadas con la deidad de la tierra. Entre estas deidades se encontraban Xilonen, Chicomecóatl, y Cozcamiauh, entidades sagradas que re-

y Bernardino de Sahagún, Historia general de las cosas de la Nueva España, introd., paleografía, glosario y notas de Josefina García Quintana y Alfredo López Austin, México, Consejo Nacional para la Cultura y las Artes, 1989, vol. I, p. 93.

16 Kauffmann, op. cit., p. 206-207 y Sahagún, op. cit., vol. I, p. 202.

17 Kauffmann-Doig, op. cit , p. 207 


\section{EL CULTO A LA TIERRA, LOS MONTES Y EL AGUA}

presentaban al maíz en sus tres fases, que correspondían al desarrollo de una mujer: juventud, madurez y ancianidad. Según el mito de Pachacámac, Pachamama imploró para que el ser humano tuviera sustento, así fue fecundada por el dios personificado por un ave ${ }^{18}$. La otra mujer de Pachacámac, llamada Urpay Huachac, fue la diosa que dio lugar a las especies marinas y a las aves del litoral, por tanto Pachamama y Urpay Huachac fueron las encargadas de proporcionar la subsistencia al ser humano ${ }^{19}$. Las narraciones mitológicas nahuas consignan que del cuerpo de la deidad terrestre surgieron los diversos vegetales, pero los alimentos quedaron encerrados en una montaña. Fue el dios Quetzalcóatl quien los encontró, pero los tlaloque o dioses de la lluvia, quienes abrieron el cerro, se adueñaron de las plantas alimenticias y se las llevaron a su recinto, el Tlalocan. Otro mito refiere que el dios Piltzintecuhtli se introdujo debajo de la tierra y sus diversas partes del cuerpo dieron lugar a las diferentes plantas alimenticias. Por otro lado, Mamacocha, divinidad del mar, estaba asociada a Pachamama. Entre los mexicas, el equivalente de esa deidad fue Chalchiuhtlicue, consorte del dios de la lluvia. Estas divinidades marinas representaban las aguas originales, entidad a la que atribuían la facultad de la fertilidad, por eso en ambos casos fueron comunes las ofrendas de conchas y caracoles, que tenían como objetivo atraer la lluvia y propiciar la generación de los alimentos. Bernardino de Sahagún y Diego Durán refieren que los nahuas creían que el agua de mar se filtraba por innumerables caminos subterráneos que tenía la tierra y, debido a ello, se formaban los manantiales, algunos ríos y las lagunas ${ }^{20}$.

\section{LAS MONTAÑAS COMO ENTIDADES SAGRADAS}

El predominio del paisaje accidentado, tanto en la región andina como en Mesoamérica, propició que algunos accidentes geográfi-

18 Ibid., p. 206-207.

19 María Rostworowski de Diez Canseco, Pachacámac y el señor de los milagros. Una trayectoria milenaria, Lima, Perú, Instituto de Estudios Peruanos, 1992, p. 37 (Serie: Historia Andina, 19).

20 Sahagún, op. cit., vol. II, p.800 y Durán, op. cit., vol. I, p. 91. 


\section{SILVIA LIMÓN OLVERA}

cos, como los montes, las quebradas y las cuevas, fueran interpretados por los pueblos indígenas como lugares sagrados, ya que en esos sitios era posible el contacto con seres sobrenaturales. Además, determinados montes fueron identificados como dioses o personajes míticos. De igual forma, algunos cerros representan la reproducción de la montaña cósmica que se encuentra en el centro del mundo, por ello señalan el eje vertical que permite la unión del mundo alto o cielo con la tierra y el inframundo, es decir, también son reproducciones del eje cósmico. De esta manera, los montes son identificados como espacios sagrados, pues en ellos se manifiestan las fuerzas de los dioses. En relación con esto, Juan de Santa Cruz Pachacuti menciona que el dios Tonapa predicó en el cerro de Cara Puco y estuvo un tiempo en una peña llamada Titicaca; asimismo, refiere que Cusco se fundó en un sitio donde también había una peña ${ }^{21}$. Por tanto, dicho accidente geográfico corresponde a una hierofanía, es decir, señala un sitio privilegiado, puesto que es manifestación de lo sagrado. En el caso de los mexicas, la ciudad de México Tenochtitlan fue fundada en un islote, en medio de un lago, elemento natural que bien puede simbolizar un monte, por ser una protuberancia que sobresale del agua.

Por otra parte, la montaña cósmica del centro constituye un sitio privilegiado en los mitos, puesto que en ese punto fue donde se generó la vida y los dioses procedieron a ordenar el mundo. Según algunos mitos andinos prehispánicos, fue en una montaña donde se llevó a cabo la creación. De acuerdo con una tradición, ésta fue efectuada por el dios Viracocha en la isla del lago Titicaca, la cual es mencionada en algunas fuentes como monte, debido a la latitud en la que se encuentra ${ }^{22}$. En dicha isla, Viracocha creó el Sol y la Luna, astros que se elevaron al cielo al recibir la orden de la deidad crea-

21 Juan de Santa Cruz Pachacuti Yamqui Salcamaygua, Relación de antigüedades deste reyno del Piru, edición facsimilar y transcripción paleográfica del Códice de Madrid, estudio etnohistórico y lingüístico de Pierre Duviols y César Itier, Cusco, Perú, Institut Francais D'Études Andines, Centro de Estudios Regionales Andinos Bartolomé de las Casas, 1993, f. $5 v$ y f. 8.

22 Ibid., f. $5 v$ y Pedro Sarmiento de Gamboa, Historia de los Incas. Segunda. parte de la historia general llamada índica, Madrid, España, Miraguano Ediciones y Ediciones Polifemo, 1988, 192 p. 


\section{EL CULTO A LA THERRA, LOS MONTES Y EL AGUA}

dora ${ }^{23}$. Por otro lado, fue también en ese sitio donde dicha divinidad creó a los antepasados de los diferentes grupos humanos, a quienes les ordenó que se sumergieran en las entrañas de la tierra para que cada uno fuera a salir por un punto específico de la región que les correspondería poblar. Estos sitios de origen, llamados pakarinas, fueron las lagunas, los manantiales, las cuevas y las quebradas, pero la isla del lago Titicaca fue considerada como la pakarina por excelencia. En relación con esto, hay que considerar que los mexicas y los incas tuvieron su principio en cuevas localizadas al interior de cerros: Chicomóztoc, las siete cavidades que se encontraban en el cerro de Teoculhuacan y las tres cavernas o ventanas localizadas en el cerro Tampu Tocco. En los dos casos, además, esos sitios fueron el punto inicial de la migración de dichos pueblos en su búsqueda del lugar prometido por sus respectivos dioses ${ }^{24}$.

En la cosmovisión andina, las montañas tuvieron un lugar privilegiado, ya que eran consideradas huacas, debido a que eran entidades vivas de carácter sobrenatural, cargadas de sacralidad, poseedoras de un espíritu (camaquén) y con las cuales el hombre tenía vínculos estrechos ${ }^{25}$. Así, los antiguos pobladores andinos veneraban todas las cumbres cubiertas de nieve, $y$ algunos montes alrededor de Cusco eran especialmente sagrados, pues representaban a personajes míticos y a dioses. Esta concepción también es válida para Mesoamérica, puesto que en esta región las montañas eran asimismo consideradas como entidades vivas y sagradas. De acuerdo con Sahagún, para los mexicas los montes eran los contenedores de agua del mundo y representaban a los tlaloques o dioses de la lluvia ${ }^{26}$.

Según las concepciones mesoamericanas y andinas, existió una liga íntima entre los pueblos y el medio geográfico, que se manifestó a través de relaciones de interdependencia y de intercambio recíproco de ofrendas y dones. En estas cosmovisiones, los montes

23 Pedro Sarmiento de Gamboa, op. cit., p. 43.

24 Silvia Limón Olvera, Las cuevas y el mito de origen. Los casos inca y mexica, México, Consejo Nacional para la Cultura y las Artes, 1990.

25 Kauffmann-Doig, op. cit., p. 199.

26 Sahagún, vol. I, p. 


\section{SILVIA LIMÓN OLVERA}

fueron caracterizados como entidades protectoras de las comunidades y fueron objeto de culto por personificar a algunas deidades o por estar relacionados, de manera sobrenatural, con la agricultura. De ésta forma, diversos pueblos, en ambas zonas, establecieron relaciones de parentesco con determinados montes, puesto que creían que su progenitor remoto, identificado con su dios protector, habitaba en alguna montaña cercana, desde donde vigilaba, cuidaba y ayudaba a sus descendientes ${ }^{27}$. En relación con lo anterior, para los aimaras, la Pachamama y los achachilas o montes constituyen fuerzas sobrenaturales benéficas para el hombre, por eso los campesinos les piden bendiciones, protección y les dan gracias por los favores recibidos. Para ellos la tierra es su madre y los montes sus abuelos, pues consideran que sus antepasados remotos tomaron posesión de las altas montañas de los Andes, desde donde cuidan y ayudan a sus descendientes, pero, al mismo tiempo, personifican a las fuerzas sagradas de los montes y de las nubes ${ }^{28}$.

En las religiones mexica e incaica, los cerros personificaban a las fuerzas sagradas que determinaban los fenómenos meteorológicos, ya que tanto Illapa como los tlaloque residían en ellos y desde alli enviaban la lluvia a los campos de cultivo ${ }^{29}$. Según la cosmovisión andina, las montañas más altas o apus servían de morada a los huamanis, halcones míticos que eran manifestación de Illapa ${ }^{30}$. Por otro lado, en las cuevas, que son parte integral de muchas montañas, se encontraba el germen de la vida representado por el agua, la cual era necesaria para la producción agrícola. De esta forma, la esencia de la lluvia se encontraba resguardada en algunas cuevas, pues, según refiere la Relación de Huamachuco, el agustino fray Juan Ramírez encontró una caverna, en cuyo interior había un ídolo de piedra, llamado Llaiguen, rodeado de ofrendas, ya que los habitantes de esa región le rendían una gran veneración porque

27 Berg, op. cit., p. 297, 299 y 301 y Alfrefdo López Austin, Breve historia de la tradición religiosa mesoamamericana, México, UNAM-IIA, 1999, p. 34-35

28 Berg, op. cit., p. 297, 299 y 301.

29 Ibid., p. 297.

30 Kauffmann-Doig, op. cit., p. 207. Según este mismo autor, desde la conquista hasta hoy en día Illapa ha sido identificado con Santiago apóstol, pues creen que este santo cabalga por las nubes. Ibid., p. 203. 


\section{EL CULTO A LA TIERRA, LOS MONTES Y EL AGUA}

consideraban que esa huaca proveía de agua ${ }^{31}$. También esa misma Relación refiere que los habitantes de esa región pedían lluvia a dos cantarillos llenos de agua que el inca Guayna Capac había dejado en una montaña. Por eso, cuando había sequía, los sacerdotes iban a pasar dos días a esa sierra fría y ventosa para solicitar la caída de la lluvia al agua de esos recipientes ${ }^{32}$. Sin embargo, las cuevas también podían contener elementos que dañaban a las sementeras, ya que Bernabé Cobo registra que la antigua población cusqueña creía que de la cueva llamada Ciracoya salía el granizo, por lo que le hacían ofrendas para evitar que éste fuera liberado y afectara los cultivos $^{33}$.

Concepciones semejantes a éstas las encontramos en México, donde todavía son comunes los ritos que algunas comunidades indígenas realizan en las cuevas con el objeto de pedir lluvia y conjurar su exceso o las granizadas. Por otra parte, diversas referencias en las crónicas del siglo XVI muestran que para los nahuas la tierra estaba muy relacionada con el dios pluvial Tláloc, nombre que Diego Durán interpreta como "camino debajo de la tierra" o "cueva larga" y que Thelma Sullivan traduce como "el que está hecho de tierra" y "el que es la personificación de la tierra". ${ }^{34}$ Por tanto, en la religión mexica, Tláloc y Tlaltecuhtli, dios de la tierra, estuvieron muy relacionados.

\section{CULTO A LAS MONTAÑAS}

Debido al carácter sacro de las montañas, éstas fueron objeto de culto, ya que algunas de ellas fueron de particular importancia en algunas ceremonias. En la zona andina, las ofrendas más comunes

31 Relación de la religión y ritos del Perú hecha por los padres agustinos, edición, estudio preliminar y notas de Lucila Castro de Trelles, índices c nomástico y toponímico por Miguel Ángel Rodríguez Rea, Lima, Perú, Pontificia Universidad Católica del Perú, 1992, CXII + 78 p. (Clásicos Americanos, 8).p. 22.

32 Relación de la religión, op. cit., p. 26.

33 Bernabé Cobo, Historia del Nuevo Mundo, notas e ilus. de Marcos Jiménez de la Espada, Sevilla, España, Imp. E. Rasco, 1890-1895, p. 14

34 Durán, op. cit., vol. I, p. 81 y Thelma D. Sullivan, "Tlaloc: A new ethyological interpretation of the God's name and what it reveals of his essence and nature", en XL Congreso Internacional de Americanistas, Roma, vol. II, p. 216. 


\section{SILVIA LIMÓN OLVERA}

que les daban eran piedras, hojas de coca al natural o mascadas, cejas y pestañas que se arrancaban los ofrendantes $y$ libaciones de chicha, al tiempo que recitaban plegarias breves y reiterativas. Asimismo, fue común la ofrenda de gran cantidad de cuyes y camélidos.

Entre los montes a los que los incas rendían culto estaban Tampu Tocco, montaña de cuya cueva salieron los fundadores del linaje de los incas y punto de inicio de la peregrinación; y el cerro Guanacauri, que marca el fin de la migración y la cercanía del sitio prometido. De acuerdo con los cronistas, a estos dos montes les daban la ofrenda más importante y valiosa, que consistía en el sacrificio de infantes. En la fiesta de Capac Raymi, el grupo dirigente ofrecía oro, plata y diez niños al cerro de Tampu Tocco. Mientras que al cerro Guanacauri, símbolo también de la dinastía gobernante, le ofrecían un niño y una niña. Sobre la importancia de este último monte, Pedro Cieza de León dice lo siguiente:

"Después del templo de Coricancha, era la segunda guaca de los incas el cerro de Guanacaure, que está a vista de la ciudad y era por ellos muy frecuentado y honrado, por lo que algunos dicen que el hermano del primer inca se convirtió en aquel lugar en piedra al tiempo que salieron de Pacaritambo [...] Y había antiguamente en este cerro oráculo pordonde el maldito demonio hablaba y estaba enterrado a la redonda suma grande de tesoros y en algunos días sacrificaban hombre y mujeres, a los cuales antes de que fuesen sacrificados, los sacerdotes les hacían entender que habían de ir a servir a aquel dios que alli adoraban"35.

De igual forma, en este cerro los incas realizaban dos fiestas importantes: la investidura del soberano y el rito de paso de la pubertad de los nobles, en el cual también eran armados caballeros al horadarles el lóbulo de las orejas. Esta última ceremonia, que se llevaba a cabo en el mes de Capac Raymi, incluía diversas pruebas como competencias y una batalla fingida, todo ello en honor de 


\section{EL CULTO A LA TIERRA, LOS MONTES Y EL AGUA}

Ayar Uchu, hermano de Manco Cápac, que quedó como huaca en ese lugar.

En las dos regiones, los cronistas refieren la realización de algunos ritos en los cerros, que tenían como objetivo propiciar la caída de la lluvia y asegurar, con ello, el adecuado desarrollo de los cultivos. Por tanto, esas ceremonias estaban relacionadas con la agricultura y presentaban elementos simbólicos asociados a esa actividad. En primer lugar, hay que llamar la atención sobre el hecho de que tanto a lllapa como a Tláloc les daban diversas ofrendas, entre las que destacaba el sacrificio de infantes, que tenía como finalidad generar buen tiempo y fomentar la productividad de la tierra. En el caso de los incas, los infantes eran ofrecidos al manantial Corcorcupio, en Cusco, y al cerro Chuquipalta; mientras que los mexicas los ofrendaban en el sumidero de Pantitlan y en diversos montes, entre los que destaca el monte Tlaloc, durante los primeros meses del año (Atlcahualo, Tlacaxipehualiztli, Tozoztontli y Huey Tozoztli) ${ }^{36}$. Entre los mexicas, la forma más común de sacrificar niños era por degollamiento, aunque también se menciona la práctica de ahogarlos al sumergirlos en la laguna o al encerrarlos en una cueva $^{37}$. Los incas, por su parte, acostumbraban a enterrarlos vivos, por lo que, en estos dos últimos casos, dicha ofrenda también estaba dedicada a la tierra, pues favorecía la revitalización de la parte baja del mundo y el crecimiento de las plantas.

Otro elemento ritual común para pedir lluvia fueron las procesiones que realizaban en los cerros. Los incas practicaban estas peregrinaciones en los meses de Cápac. Raymi y Uma Raymi y en ellas intervenía toda la población. Durante su realización, los participantes debían emitir llantos y fuertes gemidos para atraer las nubes y propiciar la caída del líquido celeste $e^{38}$. Por su parte, los mexicas, en el mes de Huey Tozoztli, realizaban una procesión a la cumbre

36 Cobo, op. cit., p. 15, 21 y 24 y Sahagún, op. cit., v. I, p. 81, 84 y 104-105.

37 Durán, op. cit., v. I, p. 84 y 88 y Toribio de Benavente Motolinia, Historia de los indios de la Nueva España. Relación de los ritos antiguos, idolatrías y sacrificios de los indios de la Nueva España y de la maravillosa conversión que Dios en ellos ha obrado, estudio crítico, apéndices, notas e índice de Edmundo O'Gorman, México, Porrúa, 1973, p. 35 y 36.

38 Guamán Poma de Ayala, op. cit., v. I, p. 210 y 229. 


\section{SILVIA LIMÓN OLVERA}

del monte Tláloc, en donde había un templo en cuyo interior se encontraba la imagen del dios de la lluvia rodeado de diversos idolillos que representaban a los cerros. A diferencia de los incas, en esta ceremonia sólo participaban los nobles del valle de México y de Tlaxcala ${ }^{39}$. Sin embargo, al igual que entre los incas, tanto en esta fiesta como en la de Atlcahualo, era de buen augurio que los niños que iban a ser inmolados vertieran lágrimas, pues ello significaba que habría buenos temporales ${ }^{40}$. Por tanto, con base en lo anterior, vemos que algunas de las ceremonias efectuadas por los dos pueblos en los cerros estaban destinadas a los dioses de la lluvia, pues estas divinidades estaban asociadas a los montes y tenían por objeto propiciar el buen desarrollo de la agricultura.

Los incas y los mexicas también solían hacer ceremonias en las montañas para ofrecer las primicias de las cosechas. En el mes de Inti Raymi, cuando desgranaban el maíz, los incas llevaban como ofrenda al monte Mantocalla muchos trozos de leña labrada que eran vestidos con atuendos de hombres y mujeres, así como una gran cantidad de mazorcas de maíz hechas de madera. Después de una borrachera ritual, quemaban esas imágenes junto con varias llamas. En esta misma celebración, los nobles efectuaban sacrificios a las imágenes de Viracocha, Inti e Illapa y hacían también ofrendas a los cerros de Chuquicancha, Paucarcancha y Pilocancha ${ }^{41}$. Por otra parte, los mexicas, en el mes de Tepeilhuitl, época en que las plantas estaban ya casi maduras, realizaban una fiesta en la que honraban a Tláloc, a Chalchiuhtlicue, diosa del agua, y a los montes. Parte de esta ceremonia consistía en subir a la cima de los cerros y encender fuego para solicitar que las cosechas fueran fructíferas y conjurar el hambre ${ }^{42}$. Esta práctica se conservó en el siglo XVII, ya que Pedro Ponce registra que, en esa época, los indígenas acostumbraban a dedicar las primicias de las cosechas al fuego en los cerros. En esta última celebración ofrecían mazorcas, caucho, la resina olorosa llamada copal y colocaban unas camisillas de papel

39 Durán, op. cit., v. I, p. $82-83$ y 253.

40 Sahagún, op. cit., v. I, p. 106.

41 Cobo, op. cit., p. 34.

42 Durán, op. cit., v. I, p. 165. 
a algunas piedras. También ofrendaban una gallina guisada y bollos de masa de maíz llamados tamales, alimentos que luego eran ingeridos por los participantes ${ }^{43}$. En las fiestas aquí referidas encontramos sorprendentes similitudes, a pesar de las particularidades de cada una de ellas, ya que, en los Andes y en el altiplano central de México, dichas ceremonias estaban asociadas con la cosecha, tenían lugar en cerros y hacían ofrendas al fuego para que la producción agrícola fuera abundante.

\section{RECAPITULACIÓN FINAL}

En el desarrollo de este trabajo hemos podido apreciar que las cosmovisiones indígenas que se desarrollaron en la época prehispánica en la región andina y en Mesoamérica presentan similitudes interesantes. Sin embargo, al realizar comparaciones entre los dos sistemas religiosos, resulta de gran importancia tomar en cuenta también las diferencias y particularidades de cada uno de ellos, ya que de esta manera se puede lograr una mejor comprensión del fenómeno religiosos en ambas sociedades.

El carácter eminentemente agrícola de los dos pueblos propició la generación de una serie de consideraciones específicas en la forma de concebir el cosmos, por medio de las cuales el hombre intentó explicar el mundo, así como el darle sentido y significación a su vida. De esta manera, la agricultura orientó muchas de las creencias, como la referente al origen del hombre, e influyó de manera importante en la concepción del mundo. Por tanto, las entidades sagradas relacionadas con esa actividad, como el sol y la lluvia, ocuparon un lugar preeminente en ambos panteones y su culto abarcó gran parte del año, ya que era preciso venerarlas constantemente para propiciar las condiciones óptimas para el buen desarrollo de los cultivos. Asimismo, las creaciones intelectuales de ambas socie-

43 Pedro Ponce, "Breve relación de los dioses y ritos de la gentilidad", en Tratado de la idolatría, supersticiones, dioses, ritos, hechicerías y otras costumbres gentilicias de las razas aborígenes de México, notas, comentario y estudio de Francisco del Paso y Troncoso, $3^{a}$ ed., México, Ediciones Fuente Cultural, 1953, vol. X, p. 376. 


\section{SILVIA LIMÓN OLVERA}

dades estuvieron acordes con el medio natural en el que se desarrollaron y fueron expresadas a través de narraciones míticas y de elementos simbólicos rituales. Se observa así que las fuerzas y los componentes de la naturaleza que incidieron en la vida de la sociedad y del individuo fueron elevados a la categoría de dioses.

Con base en lo expuesto en este trabajo, podemos ver que el principio femenino estaba localizado en la tierra y en el subsuelo, aunque también algunas montañas podían tener connotación femenina. Sin embargo, la parte alta de los montes se asociaba al principio masculino fecundador, puesto que algunos dioses se establecieron en esos sitios. Aquí hay que tomar en cuenta que la cima de la "montaña sagrada" correspondía a la parte baja del cielo44. Por tanto, las montañas cumplían la función cosmológica de ser el vínculo entre el cielo y la tierra. Por ello, simbolizaban la unión de lo alto y lo bajo, lo masculino y lo femenino, representaban la conjunción de los dos principios creadores - el cielo y la tierra-que posibilitaban la generación de la vida y su renovación. Por eso, los montes pueden ser considerados como reproducciones del axis mundi y, en consecuencia, en esos sitios se manifestaban las divinidades y el hombre podía establecer comunicación con ellas.

44 Pease, Los Incas, p. 153.30 Kauffmann-Doig, op. cit., p. 207. Según este mismo autor, desde la conquista hasta hoy en día Illapa ha sido identificado con Santiago apóstol, pues creen que este santo cabalga por las nubes. Ibid., p. 203. 